\section{Subthreshold diode laser micropulse photocoagulation versus intravitreal injections of bevacizumab in the treatment of central serous chorioretinopathy}

MJ Koss, I Beger and FH Koch

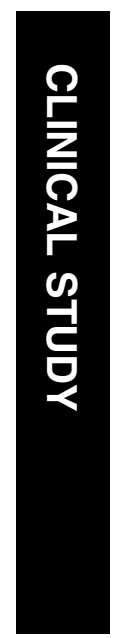

BCZ in the treatment of CSC, which resulted in enhanced visual acuity and macular perimetry.

Eye (2012) 26, 307-314; doi:10.1038/eye.2011.282;

published online 11 November 2011

Keywords: central serous chorioretinopathy; micropulse laser, subthreshold photocoagulation; bevacizumab

Introduction

Central serous chorioretinopathy (CSC) is an idiopathic disorder characterized by neuroepithelial serous detachment, with or without concomitant pigment epithelium detachment (PED) and decompensated retinal pigment epithelium (RPE) associated with one or more focal active leakage sites (ALS) at the level of the RPE ('smoke-stack' on fluorescein angiography (FA)). The underlying pathogenesis of CSC is not thoroughly understood. ${ }^{1}$ Abnormalities of choroidal circulation (most likely choriocapillaris) at indocyanine green angiography (ICGA) precede disintegration of the RPE. ${ }^{2}$ CSC may be associated with extraocular conditions, including type A personality, organ transplantation, use of steroids, systemic lupus erythematous, Cushing's disease, and other systemic factors. ${ }^{3-6}$ Blurred vision is perceived typically by patients as a dark spot in the center of the visual field with associated hyperopic shift, micropsia, and metamorphopsia, caused by anterior
Unit of Vitreo-Retinal Surgery, Department of Ophthalmology, Goethe University, Frankfurt am Main, Germany

Correspondence: MJ Koss, Unit of Vitreo-Retinal Surgery, Department of Ophthalmology, Klinikum der Johann Wolfgang Goethe-Universität Frankfurt/Main, Theodor Stern Kai 7 (Haus 7c), 60590 Frankfurt am Main, Germany Tel: +49696301 5649; Fax: + 496963015621 E-mail: Michael.Koss@ me.com

Received: 5 September 2011

Accepted in revised form: 16 September 2011 Published online: 11 November 2011 
displacement of the retinal plane because of porous RPE. Typically, CSC resolves spontaneously within 3 months in more than $50 \%$ of patients, with recovery of visual acuity (VA) despite some pigment epithelium scarring. ${ }^{5}$ Optical coherence tomography (OCT) examinations often reveal several PEDs that, when chronic, are associated with subretinal accumulation of fibrin, lipids, choriocapillaris atrophy, and choroidal neovascularization. ${ }^{1}$

Focal thermal laser photocoagulation at the ALS and grid placed over the area of RPE decompensation has been shown to promote the resolution of the serous detachment. ${ }^{7}$ However, the visible end point of conventional photocoagulation is a retinal burn that causes collateral anatomical and functional damage, and for this reason conventional laser photocoagulation is not considered as an indication in spontaneously resolving CSC and is normally deferred.

Non-thermal subthreshold diode laser MicroPulse (SDM) photocoagulation, with no visible burn end point and no collateral damage discernable at any time postoperatively, has been reported as a promising nondestructive treatment option for both subfoveal and extrafoveal lesions in CSC. ${ }^{8-10}$

MicroPulse is a laser emission technique that allows a fine control of the photothermal effects induced at the RPE level, which is very important to consistently perform effective subthreshold tissue-sparing laser treatments without visible burn end point. Unlike conventional photocoagulation where the continuous wave $(\mathrm{CW})$ laser energy causes a rapid temperature rise that spreads to produce the 'white' inner retina burn end point, MicroPulse emission can localize the thermal effects at the RPE and spare surrounding tissues and overlying neurosensory retina. In MicroPulse mode, the steady CW laser emission is 'chopped' into a train of short laser pulses separated by relatively long inter-pulse OFF time. The principles behind MicroPulse photocoagulation are quite straightforward: short MicroPulse ON time limits the laser energy and the thermal elevation, whereas long inter-pulses OFF time allows for thermal relaxation before the arrival of the next MicroPulse. Thus, MicroPulse laser emission limits the laser-induced heat rise and its thermal spread to adjacent tissues, and allows performing effective laser therapy without the tissue damage associated with conventional CW laser photocoagulation.

Theoretically, in SDM photocoagulation, each laser MicroPulse stimulates (or 'tickles') compromised RPE cells, inducing a biological response that promotes the restoration of RPE cells' integrity and physiology (ie, RPE-pump and blood-retinal barrier (BRB) functions) and, ultimately, the resorption of the subretinal fluid. ${ }^{11-13}$ The therapeutic effect of intravitreal injections of the anti-vascular endothelial growth factor (anti-VEGF) agent bevacizumab (BCZ) in the treatment of CSC has yet to be determined. BCZ has shown the ability to safely decrease intra- and subretinal fluid in the treatment of neovascular age-related macular degeneration (wet AMD), and this was also observed in the treatment of acute and chronic CSC. ${ }^{14-17}$ However, many questions remain unanswered, because other investigators have not been able to replicate this effect using similar dosage, applications, and retreatment criteria. ${ }^{18}$

The pharmacological pathway and pharmacodynamics of BCZ in CSC is poorly understood, and treatment rationale is based on the ability to decrease fluid from retina's ALS. This treatment rationale takes into account the fact that the drug penetrates all retinal layers including the RPE, with the risk of inducing iatrogenic complications, such as choriocapillaris damage, RPE atrophy, or ganglion cell damage after long-term repetitive treatment. ${ }^{19-21}$ Nevertheless, when compared with the risks of absolute and migrating scotoma associated with the current treatment options, conventional thermal laser photocoagulation or photodynamic therapy (PDT), both SDM photocoagulation and intravitreal injections of $\mathrm{BCZ}$ offer a better benefit/risk ratio in terms of clinical effectiveness and intra/postoperative safety profile and, in our view, may potentially represent better treatment modalities.

To the best of our knowledge, this study represents the first comparative, prospective evaluation of these two modalities in the treatment of CSC with regard to changes in subretinal fluid (at OCT and on FA) and in visual functions (early treatment of diabetic retinopathy study (ETDRS) VA and central macular perimetry).

\section{Patients and methods}

Fifty-two eyes of 52 patients (46 males and 6 females) were entered in this study over the period from March 2008 to April 2010. The eligibility criterion was the diagnosis of CSC with no more than two ALSs on FA. CSC was defined as RPE leakage on FA persisting at least 3 months, with or without areas of diffuse RPE decompensation and corresponding subretinal fluid accumulation evidenced at OCT. Exclusion criteria included current use, or history of use, of exogenous corticosteroids (oral, topical, intranasal, and invasive) in the 6 months before inclusion in the study, as well as diabetic retinopathy, uveitis, any hereditary retinal/macular disease, or history of intraocular surgery.

Patients' ophthalmic examination, at baseline and at 6 weeks, 6 and 10 months after treatment, included slit-lamp biomicroscopy, indirect ophthalmoscopy, ETDRS best-corrected visual acuity (BCVA), Amsler grid screening, subthreshold static automated $10^{\circ}$ perimetry 
(at baseline and at 10 months after start of study), central macular thickness (CMT) with OCT, and FA after initial treatment.

The intraocular pressure (IOP) was measured using applanation tonometry, and the CMT at the foveola was assessed by OCT in the automated mode (line and retinal thickness map mode, Model 3000 Stratus OCT, Carl Zeiss Meditec, Jena, Germany). Standard FA (FF450 plus camera, Carl Zeiss Meditec) was performed with 5 cc of $10 \%$ fluorescein (Fluorescein, Alcon, Fort Worth, TX, USA). The same protocol was repeated at each follow-up visit. The quantitative assessment of leakage was performed by a certified masked medical photographer (FL) and a masked retina specialist (FHK).

Written informed consent, clearly explaining all potential risks and possible benefits of each treatment option, SDM photocoagulation, intravitreal injections of $\mathrm{BCZ}$, or observation, was discussed with and obtained from every patient, adhering to good clinical practice regulations and the tenets of the declaration of Seoul (formerly Helsinki). The study received approval from the local investigational review board and was registered at www.clinicaltrials.gov (NCT 00802906).

Realizing that, from what it was known at the time, any of the three alternatives could have equally represented the best option for the patients, we elected in favor of a real-life random distribution with each study participant deciding their treatment of choice on the basis of the received standardized information.

At the end of the informed consent process, each patient was asked to choose a treatment group and commit to remain in that group until completion of the 10-month follow-up period.

During follow up, patients were not allowed to change groups, but repetition of treatment was possible at the decision of the principal investigator (MJK) for increased or persistent leakage.

All patients of the SDM group received SDM photocoagulation treatment performed with an 810-nm infrared diode laser (OcuLight SLx, IRIDEX Corp., Mountain View, CA, USA) delivered through the Area Centralis $\times 0.94$ laser lens (Volk Optical Inc., Mentor, $\mathrm{OH}$, USA). Before SDM photocoagulation macular treatment, a test burn was performed in the nasal mid periphery to determine the individual threshold power needed for a visible tissue reaction. The individualized test burn was performed with $125 \mu$ m spot (117 $\mu$ m on the retina), $200 \mathrm{~ms}$ exposure duration, and adjusting upward the power in the continuous wave (CW) emission mode until a light grayish visible burn was noticed. Once the threshold $\mathrm{CW}$ power $\left(\mathrm{P}_{\mathrm{cw}}\right)$ was determined, the laser was switched from $\mathrm{CW}$ into the MicroPulse emission mode set at $15 \%$ duty cycle $(0.3 \mathrm{~ms}$ 'On' time $+1.7 \mathrm{~ms}$ 'Off' time $=2.0 \mathrm{~ms}$ period $)$, the power was doubled $\left(2 \times \mathrm{P}_{\mathrm{cw}}\right)$ with the same 200-ms exposure duration (delivering a train of 100 MicroPulses), and the subthreshold macular SDM treatment was initiated. Three repeated applications were delivered at the leakage site(s), paying great attention to subtle RPE color changes during the laser treatment that would have prompted the immediate cessation of the laser treatment.

The patients of the $\mathrm{BCZ}$ group were treated with a 1.25-mg bevacizumab intravitreal injection (Avastin, Roche, Basel, Switzerland, manufactured by the compound pharmacy of the hospital of the Goethe university) according to the standard operating regulations of the hospital, with antiseptic conjunctival flush using 3\% povidone iodine (manufactured by the compound pharmacy of the hospital of the Goethe university) before the injection at the $3.5-$ to $4-\mathrm{mm}$ postlimbal inferior temporal sector. In this study with offlabel treatment modalities, retreatment criteria were chosen carefully to aim for high patient safety.

During follow-up, patients were not allowed to change groups, but retreatment with either SDM photocoagulation or intravitreal injection of $\mathrm{BCZ}$ was allowed at the decision of the principal investigator (MJK) in case of persistent, equal, or increased leakage determined by FA with the presence of equal or more subretinal fluid compared with baseline. To avoid undue risks, retreatment was not allowed if there was reduced RPE leakage with less subretinal fluid assessed by OCT. After termination of the study, all patients were granted either treatment regardless of their treatment group.

\section{Statistics}

Primary outcome measures were changes in FA, CMT, BCVA (ETDRS), and $10^{\circ}$ macular perimetry. Statistical analyses were performed using Excel (Microsoft, Richmond, VA, USA) and BiAS softwares (Version 8.2 for Windows, Epsilon-Verlag, Darmstadt, Germany). Non-normally distributed data were analyzed using David's test. The median change in CMT and ETDRS VA from baseline to each follow-up visit was analyzed using the Wilcoxon matched pairs test within each group, whereas the Mann-Whitney test was used to determine differences between the three groups.

\section{Results}

The patients' demographics and baseline characteristics are summarized in Table 1.

The patient-determined real-life random distribution resulted in 16 eyes assigned to the SDM group, 10 eyes to the BCZ group, and 26 eyes to the observation control group. 
Table 1 Demographics and baseline characteristics of patients with CSC

\begin{tabular}{|c|c|c|c|}
\hline & \multicolumn{3}{|c|}{ Group (no. of patients) } \\
\hline & $\begin{array}{l}\text { Group } 1 \text { (micropulse) } \\
\quad(\mathrm{n}=16)\end{array}$ & $\begin{array}{c}\text { Group } 2 \text { (bevacizumab) } \\
(\mathrm{n}=10)\end{array}$ & $\begin{array}{l}\text { Group } 3 \text { (control) } \\
\quad(\mathrm{n}=26)\end{array}$ \\
\hline Sex: $\mathrm{m} / \mathrm{f}$ & $14(87.5 \%) / 2(12.5 \%)$ & $9(90 \%) / 1(10 \%)$ & $23(88.5 \%) / 3(11.5 \%)$ \\
\hline Age $($ mean $\pm S D)$ & $50.8 \pm 10.9$ & $46.3 \pm 12.2$ & $49.0 \pm 11.4$ \\
\hline Eyes: R/L & $7 \mathrm{R} / 9 \mathrm{~L}$ & $6 \mathrm{R} / 4 \mathrm{~L}$ & $14 \mathrm{R} / 12 \mathrm{~L}$ \\
\hline Nicotine & $7(43.8 \%)$ & $5(50 \%)$ & $12(46.2 \%)$ \\
\hline Prior steroid use & $2(12.5 \%)$ & $2(20 \%)$ & $3(11.5 \%)$ \\
\hline Duration of symptoms - presumed duration of CSC in months & $5.3 \pm 2.1$ & $4.7 \pm 1.9$ & $5.3 \pm 2.3$ \\
\hline
\end{tabular}

${ }^{\text {a} N u m b e r s ~ a r e ~ d e p i c t e d ~ a s ~ m e a n ~ v a l u e s ~} \pm$ standard deviation.

Table 2 Laser characteristics of the MicroPulse group

\begin{tabular}{lccc}
\hline Repetitons of treatment & \multicolumn{3}{c}{ Group 1 (micropulse) } \\
\cline { 2 - 4 } & Eyes $(\mathrm{n}=16)$ & $\begin{array}{c}\text { Shots (main values and median } \\
\text { values with value range) }\end{array}$ & $\begin{array}{c}\text { Intensity (main values and median } \\
\text { values with value range })\end{array}$ \\
\hline 0 & $\mathbf{1 6}(100 \%)$ & $\mathbf{7 0 . 7}$ & $\mathbf{1 3 0 7 . 4}$ \\
1 & $\mathbf{6}(37.5 \%)$ & $62(27-136)$ & $1280(800-1740)$ \\
2 & $\mathbf{1}(6.3 \%)$ & $60(15-94)$ & $\mathbf{1 3 3 7}$ \\
Total & $23^{\mathrm{a}}$ & $89(89-89)$ & $1440(830-1530)$ \\
\end{tabular}

${ }^{\mathrm{a}}$ One patient received three treatments over 10 months follow up due to non-resolving FA-documented RPE leakage.

There were no significant differences in the demographics between the three groups.

\section{Treatment}

Eyes assigned to the SDM group received an average of 71.6 shots, with six patients requiring a second treatment and one patient a third treatment (Table 2). No tissue reactions, ie, tissue heating, were observed at any point during MicroPulse laser treatment.

In the BCZ group, after the initial injection, three patients received a second injection at 6 weeks, whereas at 6 and 10 months six patients received another $\mathrm{BCZ}$ injection owing to persistent or increasing subretinal fluid on FA and OCT. Four patients received the maximum of three injections over the 10-month follow-up period. Two patients $(3.7 \%)$ completed the study ahead of time, both at the 6-month visit. Retreatment criteria were chosen carefully to aim for high patient safety in this study with off-label treatment modalities. No patient in the three groups was using any oral, topical, inhaled, or invasive corticosteroids during the study.

\section{Outcomes}

The changes in leakage activity, CMT, BCVA, and $10^{\circ}$ macular perimetry are indicated on Tables 3-5.
Subjective Amsler grid evaluation revealed that patients in the BCZ group had persistent metamorphopsia in $80 \%$ of cases at month 10 , with two of them reporting increased or new metamorphopsia. Unlike the control group in which metamorphopsia persisted, in the SDM group a decrease of metamorphopsia became apparent in 13/16 (81.3\%) at month 10. Even at the 6-week visit, 11 eyes (68.8\%) showed noticeable improvement by Amsler grid evaluation despite $62.5 \%$ leakage activity. At the last visit, only two patients showed no change in Amsler grid, whereas the rest of the patients in the SDM group had improvement or no metamorphopsia.

No ocular adverse events, that is, intraocular inflammation, bleeding, or IOP rise, were observed.

\section{Discussion}

CSC is characterized by idiopathic serous detachment of the neurosensory retina. There are three theories on CSC pathogenesis: ${ }^{1-5}$

(1) Disorder of the outer BRB, which leads to choroidal vascular hyperpermeability. ${ }^{22}$

(2) Dysfunction of the RPE with a reversal of liquid transport.

(3) Damage of RPE due to shedding of outer photoreceptor segments with a primary intact BRB. 
Table 3 Leakage activity measured with fluorescein angiography and central macular thickness in patients with CSC before (T0) and after treatment (T1-3)

\begin{tabular}{|c|c|c|c|c|}
\hline \multirow[t]{2}{*}{ Group } & \multicolumn{4}{|c|}{ Leakage activity (LA) and CMT in mean values \pm standard deviation; Median values with value range ( $\mu m)$} \\
\hline & $\begin{array}{l}\text { Baseline } \\
\text { (T0) }\end{array}$ & $\begin{array}{l}6 \text { weeks after } \\
\text { treatment (T1) }\end{array}$ & $\begin{array}{l}6 \text { months after } \\
\text { treatment (T2) }\end{array}$ & $\begin{array}{l}10 \text { months after } \\
\text { treatment (T3) }\end{array}$ \\
\hline Group 1 (micropulse) & $\begin{array}{c}\text { LA } \\
16 / 16(100 \%) \\
\text { CMT } \\
419 \pm 59 \\
420(280-520)\end{array}$ & $\begin{array}{c}\text { LA } \\
10 / 16(62.5 \%) \\
\text { CMT } \\
387 \pm 94 \\
380(250-600) \partial 2\end{array}$ & $\begin{array}{c}\text { LA } \\
7 / 16(43.75 \%) \\
\text { CMT } \\
329 \pm 69 \\
310(220-490) \\
¥ \mathrm{~A}, ¥ \mathrm{~B} \text { and } 23\end{array}$ & $\begin{array}{c}\text { LA } \\
2 / 16(12.5 \%) ¥ 1 \\
\text { CMT } \\
325 \pm 93 \\
290(220-600) \\
¥ \mathrm{C}, ¥ \mathrm{D} \text { and } 21, \partial 4\end{array}$ \\
\hline Group 2 (Bevacizumab) & $\begin{array}{c}\text { LA } \\
10 / 10(100 \%) \\
\text { CMT } \\
393 \pm 84 \\
380(280-520)\end{array}$ & $\begin{array}{c}\text { LA } \\
3 / 10(30 \%) \\
\text { CMT } \\
355 \pm 114 \\
315(250-600) \S \mathrm{A}, \Omega 1\end{array}$ & $\begin{array}{c}\text { LA } \\
6 / 10(60 \%) \\
\text { CMT } \\
334 \pm 59 \\
345(260-410)\end{array}$ & $\begin{array}{c}\text { LA } \\
6 / 10(60 \%) \\
\text { CMT } \\
355 \pm 73 \\
320(285-500) \Omega 2\end{array}$ \\
\hline Group 3 (Control) & $\begin{array}{c}\text { LA } \\
26 / 26(100 \%) \\
\text { CMT } \\
388 \pm 59 \\
400(280-450)\end{array}$ & $\begin{array}{c}\text { LA } \\
26 / 26(100 \%) \\
\text { CMT } \\
396 \pm 57.2 \\
415(280-450)\end{array}$ & $\begin{array}{c}\text { LA } \\
24 / 26(92 \%) \\
\text { CMT } \\
388 \pm 63.4 \\
370(290-480)\end{array}$ & $\begin{array}{c}\text { LA } \\
24 / 26(92 \%) \\
\text { CMT } \\
414.5 \pm 52.7 \\
425(320-470)\end{array}$ \\
\hline
\end{tabular}

Significant differences within the groups (Wilcoxon matched pairs test) are described as:Group 1 LA - ¥1 T3 vs T0: $P=0.0005$, CMT - ¥A T2 vs T1: $P=0.0023$; ¥B T2 vs T0: $P=0.00076$, ¥C T3 vs T0: $P=0.0098$; ¥D T3 vs T1: $P=0.016$, Group 2 CMT $\$$ A T1 vs T0: $P=0.00076$.

Significant differences between the groups (Mann-Whitney test) are described as: $\partial 1$ group 1 vs group 2 LA T3 $P=0.0239$; group 1 vs group 3 d2 LA T1 $P=0.00012 ;$ o3 LA T2 $P=0.0047 ;$ o4 LA T3 $P=0.0054 ; \Omega 1$ LA T1 group2 vs group $3 P=0.0007 ; \Omega 2$ LA T3 $P=0.0344$.

Clinical improvement in VA can only be achieved with resolution of subretinal fluid. The state of the RPE is crucial in the pathophysiology and prognosis of the disease itself, and should be taken into consideration for active treatment.

Standard focal thermal laser treatment, the oldest and still questionable therapeutic option, might be effective for the coagulation of the ALS on FA. ${ }^{23}$ However, because of iatrogenic thermal damage to the neurosensory retina and the RPE, it may only be considered in extrafoveal sites to minimize the risk of laser-induced absolute scotomata, contrast sensitivity loss, accidental foveal damage, retinal distortion, rupture of Bruch's membrane, and choroidal neovascularization. ${ }^{24}$

Recently, PDT has been used when the RPE lesion is juxta-foveal or subfoveal. Pharmacologically, PDT counteracts the choroidal hyperperfusion that is one pathophysiological cornerstone of CSC development due to local choroidal thrombosis. According to Yannuzzi et $a l^{22}$ PDT treatment addresses directly the origin of subretinal fluid development. However, the optimal PDT technique, in terms of dosage, laser activation time, fluence, ICGA-guidance, and so on, is still undetermined. ${ }^{25-27}$ Furthermore, PDT can result in choroidal ischemia, RPE damage, or PDT-induced scotoma. ${ }^{28,29}$
Rather than addressing choroidal hyperperfusion, nonthermal and non-damaging SDM photocoagulation allows for the application of laser energy to subfoveal and extrafoveal lesion sites and, by stimulating (or 'tickling') a biological response in compromised RPE cells, it may induce the resolution of subretinal fluid by improving RPE cells' tight junctions and pumping functions mediated by upregulation of metalloproteinase enzymes. ${ }^{11-13}$

The 10-month results of our study cannot provide the long-term effects of SDM photocoagulation therapy in CSC, but they do indicate superior subretinal fluid resolution at month 6 and month 10, compared with observation or with intravitreal injections of BCZ. Interestingly, at week 6 , the resolution of subretinal fluid was more pronounced in the BCZ group than in the SDM group (Table 3 ). This reversed later, with the SDM group showing superior fluid resorption at the 6-month and 10-month follow-up visits, possibly indicating an enhanced pumping function resulting from the biological resetting of pathologic RPE cells that could not occur at week 6 after SDM. On the other hand, BCZ injections on a monthly basis with enhanced dosage may be more effective than in the protocol that we used in this study, taking into consideration the associated clinical and economic risks of frequent intravitreal injections. ${ }^{17}$ 
Table 4 Best corrected visual acuity in patients with CSC before (T0) and after treatment (T1-3)

\begin{tabular}{|c|c|c|c|c|}
\hline \multirow[t]{2}{*}{ Group } & \multicolumn{4}{|c|}{$\begin{array}{l}\text { Best-corrected visual acuity in mean values } \pm \text { standard deviation; Median values with value range; } \\
\qquad \text { All values in number of total letters }(T L) \text { read }\end{array}$} \\
\hline & Baseline (T0) & $\begin{array}{l}6 \text { weeks after } \\
\text { treatment (T1) }\end{array}$ & $\begin{array}{l}6 \text { months after } \\
\text { treatment (T2) }\end{array}$ & $\begin{array}{l}10 \text { months after } \\
\text { treatment (T3) }\end{array}$ \\
\hline \multirow[t]{2}{*}{ Group 1 (micropulse, $n=16$ ) } & $\begin{array}{c}\mathrm{TL} \\
45.4 \pm 7.2 \\
47(31-54)\end{array}$ & $\begin{array}{c}\text { TL } \\
47.8 \pm 6.8 \\
48.5(36-60)\end{array}$ & $\begin{array}{c}\mathrm{TL} \\
50.5 \pm 7.3 \\
52(38-62)\end{array}$ & $\begin{array}{c}\mathrm{TL} \\
51.6 \pm 7.0 \\
52(38-67)\end{array}$ \\
\hline & $\begin{array}{c}\mathrm{SE} \\
1.42 \pm 3.08 \\
0.8(-4.9 \text { to } 7)\end{array}$ & $\begin{array}{c}\text { SE } \\
1.1 \pm 2.9 \\
0.5 \text { (-4.9 to } 6.5) ¥ 1\end{array}$ & $\begin{array}{c}\text { SE } \\
0.8 \pm 2.7 \\
0.4(-5.9 \text { to } 4.3) \\
¥ 2, ¥ 3 \text { and } \partial 1, \partial 2\end{array}$ & $\begin{array}{c}\text { SE } \\
0.9 \pm 2.54 \\
0.25(-6.1 \text { to } 6.25) \\
¥ 4, ¥ 5 \text { and } 23,24\end{array}$ \\
\hline \multirow[t]{2}{*}{ Group 2 (Bevacizumab; $n=10$ ) } & $\begin{array}{c}\mathrm{TL} \\
44.1 \pm 10.8 \\
46.5(21-55)\end{array}$ & $\begin{array}{c}\mathrm{TL} \\
41.9 \pm 11.3 \\
45.5(21-54)\end{array}$ & $\begin{array}{c}\text { TL } \\
42.4 \pm 13.6 \\
49.5(20-56)\end{array}$ & $\begin{array}{c}\mathrm{TL} \\
43.5 \pm 14.5 \\
48(21-59)\end{array}$ \\
\hline & $\begin{array}{c}\text { SE } \\
0.4 \pm 1.7 \\
0.3(-2.0 \text { to } 3.0)\end{array}$ & $\begin{array}{c}\mathrm{SE} \\
0.6 \pm 2.1 \\
0.6(-3.0 \text { to } 3.8)\end{array}$ & $\begin{array}{c}\mathrm{SE} \\
0.94 \pm 1.9 \\
1.3(-2.6 \text { to } 4)\end{array}$ & $\begin{array}{c}\mathrm{SE} \\
1.0 \pm 1.74 \\
0.5(-1.8 \text { to } 3.9) \S 1\end{array}$ \\
\hline \multirow[t]{2}{*}{ Group 3 (Control, $n=26$ ) } & $\begin{array}{c}\text { TL } \\
46.4 \pm 6.1 \\
46.5(35-55)\end{array}$ & $\begin{array}{c}\mathrm{TL} \\
46.3 \pm 6.9 \\
46.5(35-55)\end{array}$ & $\begin{array}{c}\mathrm{TL} \\
44.9 \pm 5.1 \\
45(37-55)\end{array}$ & $\begin{array}{c}\mathrm{TL} \\
44.3 \pm 5.2 \\
44(36-53)\end{array}$ \\
\hline & $\begin{array}{c}\text { SE } \\
0.9 \pm 1.8 \\
0.9(-2.6 \text { to } 4.3)\end{array}$ & $\begin{array}{c}\mathrm{SE} \\
0.9 \pm 1.8 \\
0.89(-2.2 \text { to } 4.0)\end{array}$ & $\begin{array}{c}\mathrm{SE} \\
0.9 \pm 1.76 \\
1.0(-2.6 \text { to } 4.0)\end{array}$ & $\begin{array}{c}\text { SE } \\
0.9 \pm 1.75 \\
1.0(-2.6 \text { to } 4.3)\end{array}$ \\
\hline
\end{tabular}

Significant differences within the groups (Wilcoxon matched pairs test) are described as: Group 1 TL $¥ 1$ T1 vs T0 $P=0.092 ;$ TL $¥ 2$ T2 vs T0 $P=0.035$; TL $¥ 3$ T2 vs T1 $P=0.092$; TL $¥ 4$ T3 vs T0: $P=0.014$; TL $¥ 5$ T3 vs T1: $P=0.078$, Group 2 TL $\$ 1$ T3 vs T0: $P=0.078$

Significant differences between the groups (Mann-Whitney test) are described as: $\partial 1$ group 1 vs group 2 TL T2 $P=0.0001$; group 1 vs group 3 d2 TL T2P $=0.00012 ;$ 23 TL T3 $P=0.000047 ;$ 24 TL T3 $P=0.0054$

Table 5 Subthreshold static automated $10^{\circ}$ perimetry in patients with CSC before (T0) and 10 months after treatment (T3)

\begin{tabular}{|c|c|c|c|c|c|c|}
\hline \multirow[t]{3}{*}{ Group } & \multicolumn{6}{|c|}{$\begin{array}{c}\text { Subthreshold static automated } 10^{\circ} \text { perimetry }(M D, L V, C L V) \text { in mean values } \pm \text { standard deviation; } \\
\text { median values with value range }\end{array}$} \\
\hline & \multicolumn{2}{|r|}{$M D$} & \multicolumn{2}{|r|}{$L V$} & \multicolumn{2}{|r|}{$C L V$} \\
\hline & $\begin{array}{l}\text { Baseline } \\
\text { (T0) }\end{array}$ & $\begin{array}{c}\text { After } \\
\text { treatment (T3) }\end{array}$ & $\begin{array}{l}\text { Baseline } \\
\text { (T0) }\end{array}$ & $\begin{array}{c}\text { After } \\
\text { treatment (T3) }\end{array}$ & $\begin{array}{l}\text { Baseline } \\
\text { (T0) }\end{array}$ & $\begin{array}{c}\text { After } \\
\text { treatment (T3) }\end{array}$ \\
\hline Group 1 & $2.7 \pm 2.8$ & $1.2 \pm 2.9$ & $11.6 \pm 7.0$ & $9.2 \pm 6.1$ & $10.3 \pm 5.7$ & $7.7 \pm 4.8$ \\
\hline (micropulse, $n=16$ ) & $2.0(-1.2$ to 9.1$)$ & $1.0(-4.2$ to 7.8$) \partial 1, \partial 2$ & $10.3(2.4-24.4)$ & $7(2.4-25.2) \Omega 1, \Omega 2$ & $10.1(3-20.4)$ & $6.1(1.1-16.9) \S 1, \S 2$ \\
\hline Group 2 & $5.9 \pm 2.3$ & $4.1 \pm 4.9$ & $21.7 \pm 15.5$ & $24.4 \pm 20.3$ & $19.6 \pm 14.9$ & $19.0 \pm 19.4$ \\
\hline (Bevacizumab; $n=10$ ) & 6.3 (2.9 to 9.3$)$ & $2.8(-0.7$ to 9.4$)$ & $16.6(8.3-56)$ & $20(2.1-58.4)$ & $13.4(7.1-49.9)$ & $8.9(0.6-49.9)$ \\
\hline Group 3 & $3.5 \pm 3.1$ & $3.9 \pm 2.9$ & $12.9 \pm 7.8$ & $11.1 \pm 7.1$ & $10.8 \pm 6.4$ & $10.3 \pm 6.2$ \\
\hline (Control, $n=26$ ) & $2.9(-1.2-9.3)$ & $2.8(-0.7$ to 9.4$)$ & $10.5(3.4-23.2)$ & $10.8(1.1-18.3)$ & $10.6(3-19.6)$ & $10.7(3.2-19.1)$ \\
\hline
\end{tabular}

MD, Mean deficit; LV, lost variance; CLV, corrected lost variance.

Significant differences between the groups (Mann Whitney test) are described as: 21 group 1 vs group 2 MD $P=0.0001$; group 1 vs group 3 22 MD $P=0.0012 ; \Omega 1$ group 1 vs group $2 \mathrm{LV} P=0.0001 ; \Omega 2$ group2 vs group $3 \mathrm{LV} P=0.0001 ; \S 1$ group 1 vs group $2 \mathrm{CLV} P=0.0001 ; \S 2$ group 1 vs group $3 \mathrm{CLV}$ $P=0.0001$

Because all patients were treated and retreated with the same criteria (stronger leakage on FA with presence of more subretinal fluid than baseline), there was no bias to undertreat one group. The two patients with persistent leakage in the SDM group had two leakage sites and were male non-smokers. However, the nonresponders in the $\mathrm{BCZ}$ group had no common features in type of leakage, gender, or smoking habits. The decrease in subretinal fluid was most pronounced in the SDM group, but, because the retreatment criterion was active leakage 
on FA, some degree of subretinal fluid was observed in all groups at month 10 . It is not clear whether additional SDM photocoagulation could have further decreased the subretinal fluid in these cases. This evaluation was not the goal of this study, but ongoing studies are in progress to examine this clinical setting.

No tissue reactions, that is, tissue heating, were observed during and at any point after the SDM photocoagulation treatment (Table 2), but long-term complications are not impossible and cannot be ruled out. To monitor the effects of photoreceptor/RPE dysfunction, we performed $10^{\circ}$ perimetry, a rather indirect and subjective functional parameter. One limitation of our study is that $10^{\circ}$ perimetry was performed without fixation control; therefore, we could not detect the possibility of scotoma development after the SDM photocoagulation treatment.

However, the $\mathrm{BCZ}$ group and the control groups indicated slight scotoma enhancement. Other studies have shown that intravitreal anti-VEGF agents effectively resorb subretinal fluid in up to $80 \%$ of the cases, ${ }^{14}$ whereas our study showed resolution only in $40 \%$ of the cases after 10 months. Our study seems to be the most thorough study on the intravitreal injection of BCZ treatment in CSC to date. Compared with SDM photocoagulation, intravitreal $\mathrm{BCZ}$ seems to reduce subretinal fluid faster, but requires frequent reinjections, regardless of the dosage. We used $1.25 \mathrm{mg}$ of $\mathrm{BCZ}$ as described by Inoue et $a l^{15}$ whereas some groups used $2.5 \mathrm{mg} .{ }^{14,17}$

In our study, unlike in exudative AMD, intravitreal anti-VEGF injections were not associated with long-term damage to the RPE, the choriocapillaris, or the ganglion cells. However, CSC patients are usually younger, and ongoing intravitreal injections might not be a sustainable therapy. In addition, we should point out that this is a non-randomized study and there can be factors that may have potentially influenced the patients' choice between the treatment groups. It may be of interest that, on the basis of the data and information available at the time, which was clearly explained in our standardized informed consent process, 50\% (26/52) of the patients elected to be assigned to the observation control group, which is still the current standard of care, $31 \%(16 / 52)$ opted for a minimally invasive intervention signing in the SDM photocoagulation group, and 19\% (10/52) preferred the pharmacological intervention with intravitreal injections of BCZ. Thus, it was not a randomized trial but rather a real-life distribution with the bias that a patient, who opted for the SDM intervention is different by own decision and a biased selection over a patient with BCZ or no therapy. More studies should be conducted in the future, and our group is currently examining by randomization SDM with PDT in CSC in an ongoing trial.

Conversely, because of the absence of laser-induced retinal damage discernable at any time postoperatively, SDM photocoagulation, with no focal burn end point (or its consequences), represents an elegant medical approach and a true clinical alternative.

In conclusion, in this 10-month prospective, controlled study, SDM photocoagulation resulted superior to the intravitreal injections of $1.25 \mathrm{mg} \mathrm{BCZ}$ for resolution of subretinal fluid secondary to CSC. BCVA, macular perimetry, and metamorphopsia were improved after SDM photocoagulation, whereas the observed control group showed no improvements. The use of anti-VEGF injections as a monotherapy, or as adjunctive therapy, should be investigated in the future.

\section{Summary}

What was known before

- There is no goldstandard treatment for CSC. The current treatments have not been compared with each other prospectively

What this study adds

- This comparative, controlled, prospective clinical study over 10 months, which we conducted over 2 years in Frankfurt, assessed superiority of micropulse over $1.25 \mathrm{mg}$ bevacizumab intravitreal injections.

\section{Conflict of interest}

The authors declare no conflict of interest.

\section{Acknowledgements}

The authors thank the Messer Foundation in Königstein Germany for their support.

\section{References}

1 Klais CM, Ober MD, Ciardella AP, Yannuzzi LA. Central Serous Chorioretinopathy. In: Ryan SJ (ed.). Retina Vol. II Elsevier: Philadelphia, 2006, pp 1135-1161.

2 Guyer DR, Yannuzzi LA, Slakter JS, Sorenson JA, Ho A, Orlock D. Digital indocyanine green videoangiography of central serous chorioretinopathy. Arch Ophthalmol 1994; 112(8): 1057-1062.

3 Carvalho-Recchia CA, Yannuzzi LA, Negrao S, Spaide RF, Freund KB, Rodriguez-Coleman $\mathrm{H}$ et al. Corticosteroids and central serous chorioretinopathy. Ophthalmology 2002; 109(10): 1834-1837.

4 Mudvari SS, Goff MJ, Fu AD, McDonald HR, Johnson RN, Ai $\mathrm{E}$ et al. The natural history of pigment epithelial detachment associated with central serous chorioretinopathy. Retina 2007; 27(9): 1168-1173. 
5 Wang M, Munch IC, Hasler PW, Prunte C, Larsen M. Central serous chorioretinopathy. Acta Ophthalmol 2008; 86(2): 126-145.

6 Yannuzzi LA. Type A behavior and central serous chorioretinopathy. Trans Am Ophthalmol Soc 1986; 84: 799-845.

7 Yannuzzi LA. Laser photocoagulation of the macula: central serous chorioretinopathy. JB Lippincott: Philadelphia, 1989, pp 3-12.

8 Chen SN, Hwang JF, Tseng LF, Lin CJ. Subthreshold diode micropulse photocoagulation for the treatment of chronic central serous chorioretinopathy with juxtafoveal leakage. Ophthalmology 2008; 115(12): 2229-2234.

9 Gupta B, Elagouz M, McHugh D, Chong V, Sivaprasad S. Micropulse diode laser photocoagulation for central serous chorio-retinopathy. Clin Experiment Ophthalmol 2009; 37(8): 801-805.

10 Lanzetta P, Furlan F, Morgante L, Veritti D, Bandello F. Nonvisible subthreshold micropulse diode laser $(810 \mathrm{~nm})$ treatment of central serous chorioretinopathy. A pilot study. Eur J Ophthalmol 2008; 18(6): 934-940.

11 Colome J, Ruiz-Moreno JM, Montero JA, Fernandez E. Diode laser-induced mitosis in the rabbit retinal pigment epithelium. Ophthalmic Surg Lasers Imaging 2007; 38(6): 484-490.

12 Dorin G. Subthreshold and micropulse diode laser photocoagulation. Semin Ophthalmol 2003; 18(3): 147-153.

13 Flaxel C, Bradle J, Acott T, Samples JR. Retinal pigment epithelium produces matrix metalloproteinases after laser treatment. Retina 2007; 27(5): 629-634.

14 Artunay O, Yuzbasioglu E, Rasier R, Sengul A, Bahcecioglu $H$. Intravitreal bevacizumab in treatment of idiopathic persistent central serous chorioretinopathy: a prospective, controlled clinical study. Curr Eye Res 2010; 35(2): 91-98.

15 Inoue M, Kadonosono K, Watanabe Y, Kobayashi S, Yamane S, Arakawa A. Results of one-year follow-up examinations after intravitreal bevacizumab administration for chronic central serous chorioretinopathy. Ophthalmologica 2010; 225(1): 37-40.

16 Lim SJ, Roh MI, Kwon OW. Intravitreal bevacizumab injection for central serous chorioretinopathy. Retina 2010; 30(1): 100-106.

17 Schaal KB, Hoeh AE, Scheuerle A, Schuett F, Dithmar S. Intravitreal bevacizumab for treatment of chronic central serous chorioretinopathy. Eur J Ophthalmol 2009; 19(4): 613-617.
18 Lim JW, Ryu SJ, Shin MC. The effect of intravitreal bevacizumab in patients with acute central serous chorioretinopathy. Korean J Ophthalmol 2010; 24(3): 155-158.

19 Baffert F, Le T, Sennino B, Thurston G, Kuo CJ, Hu-Lowe D et al. Cellular changes in normal blood capillaries undergoing regression after inhibition of VEGF signaling. Am J Physiol Heart Circ Physiol 2006; 290(2): H547-H559.

20 Iriyama A, Chen YN, Tamaki Y, Yanagi Y. Effect of anti-VEGF antibody on retinal ganglion cells in rats. Br J Ophthalmol 2007; 91(9): 1230-1233.

21 Kamba T, Tam BY, Hashizume H, Haskell A, Sennino B, Mancuso MR et al. VEGF-dependent plasticity of fenestrated capillaries in the normal adult microvasculature. Am J Physiol Heart Circ Physiol 2006; 290(2): H560-H576.

22 Yannuzzi LA, Shakin JL, Fisher YL, Altomonte MA. Peripheral retinal detachments and retinal pigment epithelial atrophic tracts secondary to central serous pigment epitheliopathy. Ophthalmology 1984; 91(12): 1554-1572.

23 Robertson DM, Ilstrup D. Direct, indirect, and sham laser photocoagulation in the management of central serous chorioretinopathy. Am J Ophthalmol 1983; 95(4): 457-466.

24 Landers III MB, Shaw Jr HE, Anderson Jr WB, Sinyai AJ. Argon laser treatment of central serous chorioretinopathy. Ann Ophthalmol 1977; 9(12): 1567-1572.

25 Koytak A, Erol K, Coskun E, Asik N, Ozturk H, Ozerturk Y. Fluorescein angiography-guided photodynamic therapy with half-dose verteporfin for chronic central serous chorioretinopathy. Retina 2010.

26 Ober MD, Yannuzzi LA, Do DV, Spaide RF, Bressler NM, Jampol LM et al. Photodynamic therapy for focal retinal pigment epithelial leaks secondary to central serous chorioretinopathy. Ophthalmology 2005; 112(12): 2088-2094.

27 Yannuzzi LA, Slakter JS, Gross NE, Spaide RF, Costa DL, Huang SJ et al. Indocyanine green angiography-guided photodynamic therapy for treatment of chronic central serous chorioretinopathy: a pilot study. Retina 2003; 23(3): 288-298.

28 Lee PY, Kim KS, Lee WK. Severe choroidal ischemia following photodynamic therapy for pigment epithelial detachment and chronic central serous chorioretinopathy. Jpn J Ophthalmol 2009; 53(1): 52-56.

29 Ozmert E, Batioglu F. Fundus autofluorescence before and after photodynamic therapy for chronic central serous chorioretinopathy. Ophthalmologica 2009; 223(4): 263-268. 